\title{
Parents' attitude towards their children and adolescents affected by leprosy in an endemic district in West Bengal, India
}

\author{
Joydeepa Darlonga \& Pitchaimani Govindharaj ${ }^{\mathrm{b}, \mathrm{c}}$ \\ ${ }^{\mathrm{a}}$ Head, Knowledge and Management, The Leprosy Mission Trust India, \\ NewDelhi, India \\ ${ }^{\mathrm{b}}$ Physiotherapist (at time of study), The Leprosy Mission Hospital, Purulia, \\ West Bengal, India \\ ${ }^{\mathrm{c}}$ Lecturer, Department of Allied Health Sciences, Sri Ramachandra Institute \\ of Higher Education and Research, Chennai, Tamil Nadu, India
}

Submitted 20 July 2020; Accepted 10 August 2020

\begin{abstract}
Summary
Background: Parental attitude is an important area to study in order to improve services to families of children affected by leprosy, as it plays a major role in the diagnosis and treatment of the sick child. This study examines parents' attitudes towards their children affected by leprosy.

Methods: This field-based study sample consisted of 100 couples who had registered their children for treatment at a tertiary care hospital. Parental attitude towards their children's illness was measured using the Parents Attitude Towards Children Illness Scale (PATCIS).

Results: One hundred couples were interviewed, these being the parents of 60 male and 40 female children with leprosy. Of these children, 67 were diagnosed as multibacillary. Almost all of them had a skin patch as the first symptom: 46 children noticed the patch themselves and 51 were noticed by the parents. Forty-nine cases had started treatment within six months after noticing the patch. The overall mean score of the study participants was $4.19 \pm 3.44$, showing that most of them had a positive attitude towards the disease of their children.

Conclusion: This is the first study to investigate the parents' attitude towards their children affected by leprosy. The study showed that the parents had a positive attitude towards their child's disease.
\end{abstract}

Keywords: Parents attitude, leprosy, attitude, stigma, Childhood leprosy

Correspondence to: Joydeepa Darlong, Head - Knowledge and Management, The Leprosy Mission Trust India, New Delhi, India (e-mail: joydeepa.darlong@leprosymission.in) 


\section{Introduction}

Leprosy is one of the oldest diseases known to mankind. India still has the largest number of leprosy affected in terms of the absolute number of cases, prevalence and incidence. ${ }^{1}$ Globally, 208,641 new leprosy cases were detected in 2017-18, among whom $60 \%$ were from India. ${ }^{2}$ In India, a total of 135,485 new cases were detected during the year 2016-17, and the prevalence rate (PR) was 0.66 per 10,000 population as of 1st April, 2017. Among new cases, a total of $11,792(8.70 \%)$ were children below 15 years of age. ${ }^{3}$

Every year, a large number of new leprosy cases are registered in Purulia district, which is located in the state of West Bengal, India. As of March, 2017, Purulia district had a prevalence rate (PR) of 2.37 per 10,000 population, and an annual new case detection rate (ANCDR) of 52.47 per 100,000 population. ${ }^{4}$

The Leprosy Mission Hospital, Purulia, is a referral hospital located in the district of Purulia. Six hundred and thirty-four new leprosy cases were registered from January to December of 2014. Of these, 147 (23.2\%) were children or adolescents aged up to 18 years (85 males, 62 females).

From 2011 to 2013, of 2,222 new leprosy cases who were registered, 459 (20.73\%) were children under 18 years of age. Of these, $12 \%$ had grade II disability at the time of diagnosis and $12 \%$ were smear positive. Among the registered child cases from 2011 to 2014, 369 children were from Purulia district.

Despite the statistical elimination of leprosy, childhood leprosy cases continue to present in alarming numbers. Multibacillary disease and the complications of lepra reactions and deformities remain common in children. ${ }^{5}$ The child proportion amongst newly registered leprosy cases has not shown a significant decline in the years following elimination. The most important figure in the child's immediate environment is a parent. Increasingly, parents are also involved in caring for their children who are leprosy affected. The chronicity of the problems and long duration of treatment leads to stress among parents and caregivers. Emotionally, the greatest risk to which most children with leprosy are exposed is the incessant worry of parents or guardians. It may also result in complete apathy towards a sick child. When a child has a disability, problems increase in the family. ${ }^{6}$ Demands on energy, time and financial resources add to a heavy burden of stress. The literature shows that parents' attitudes are critical to the successful caring of children with illness. ${ }^{6}$ The way parents react to an ill child partly depends on how they perceive the illness and the practical impact the illness has on them. Parents' attitudes are an important source of information about their behaviour towards their children.

Children are sensitive enough to understand this. Children with leprosy suffering from the tragic consequences of disability are socially marginalized and rejected. Compliance among children depends on the parent or guardian, as they are a vulnerable section of society. In poor socioeconomic communities where the parent is a migrant labourer, compliance is usually a matter of concern. A child with disability may have anxiety, fear, shame or other negative feelings. These reactions usually reflect how the child has been treated by others, especially the family. ${ }^{7}$ An attitude may be defined as an individual's tendency to react positively or negatively to some person, object, situation, institution or event. ${ }^{8}$ In this study, the term 'attitude' is used to cover parents' behaviour, perceptions, reactions, values and feelings towards their child's illness. Studies have been conducted on knowledge, attitude and practices of people affected by leprosy. To our knowledge, there is no study that has been conducted on the attitude of parents towards their child affected by leprosy. The parents' attitudes are an important area of study in order to improve services to families of children with disability. Parental attitudes 
play a major role in the treatment and diagnosis of the sick child. ${ }^{7,9,10}$ This study examines the parents' attitudes towards their children and adolescents affected by leprosy.

\section{Methods}

The field-based study sample consisted of 100 couples of children and adolescents affected by leprosy, who were registered for treatment at The Leprosy Mission Hospital, Purulia. The study was carried over the period of three months from March 2015 to May 2015.

\section{ELIGIBILITY CRITERIA}

The study included all Bengali-speaking parents of children aged 8 to 18 years with a diagnosis of leprosy, currently on treatment for leprosy or who completed treatment during the years 2011-2014. Among the 606 registered child cases from 2011 to 2014, 369 children were from Purulia district.

\section{SEMI-STRUCTURED QUESTIONNAIRE}

A semi-structured questionnaire was used to interview both parents together. The questions covered the level of knowledge in terms of early signs and symptoms of leprosy, the cause and treatment for leprosy, knowledge and attitudes towards infectivity, curability and consequences of leprosy. Basic details of the parents such as age, sex, literacy, occupation and financial status were ascertained. The disease details and treatment status of the children and adolescents were ascertained from the medical records.

\section{PARENTS'ATTITUDE TOWARDS CHILDREN ILLNESS SCALE}

The parents' attitude was measured using the Parents Attitude Towards Children Illness Scale (PATCIS) which was developed by the authors. Items were collected through field observation, interviews with experts and from the literature. ${ }^{7,11}$ Item reduction was done and the items were converted into questions. Face validity was examined for the scale items by three experts who had experience in leprosy treatment and rehabilitation. ${ }^{12}$

The twelve item questionnaire was prepared using the 5-point Likert scale from 1 (Strongly Agree) to 5 (Strongly Disagree), to measure the parents' perceptions. The English version of scale was translated into Bengali. The Bengali version was translated back into English to confirm the integrity of the questions. A trained field investigator administered the PATCIS scale with 10 parents of children affected by leprosy, to test the developed scale. Subsequently, the investigators checked the items for consistency, understanding and terminology, including discussion with the field investigator. Finally, the resulting PATCIS scale was administered in this study.

The Bengali version was tested in the community and studied for internal consistency and reliability. An alpha between 0.7 and 0.9 was considered acceptable. ${ }^{13}$ The Cronbach's alpha score was 0.72 for the 12 -item scale. Corrected item-total correlation ranged from 0.13 to 0.56 , with 5 items falling at or above 0.40 . Cronbach's alpha scores for the scale with each individual item deleted, ranged from 0.662 to 0.722 .

\section{PROCEDURE}

A field investigator trained in interview techniques was assigned to recruit participants, describe the study to the parent(s), obtain informed consent, instruct the parents on how to answer the questionnaires and perform the interview. Detailed recruitment and questionnaire 
Table 1. Demographic details of children affected with leprosy

\begin{tabular}{|c|c|c|c|c|}
\hline & Status & Male $(n=60)$ & Female $(n=40)$ & Total $(n=100)$ \\
\hline \multirow[t]{2}{*}{ Age } & $8-14$ & 25 & 20 & 45 \\
\hline & $15-18$ & 35 & 20 & 55 \\
\hline \multirow[t]{5}{*}{ Education of child } & Primary & 6 & 5 & 11 \\
\hline & Secondary & 41 & 29 & 70 \\
\hline & Higher Secondary & 12 & 3 & 15 \\
\hline & Graduate & 1 & 2 & 3 \\
\hline & Illiterate & 0 & 1 & 1 \\
\hline Continuing & Yes & 55 & 30 & 85 \\
\hline education of child & No & 5 & 10 & 15 \\
\hline Occupation & Farmer & 19 & 14 & 33 \\
\hline \multirow[t]{3}{*}{ of Father } & Labour & 27 & 16 & 43 \\
\hline & Skilled Labour & 11 & 5 & 16 \\
\hline & $\begin{array}{c}\text { Professional \& } \\
\text { Business }\end{array}$ & 3 & 5 & 8 \\
\hline Family Income & $\begin{array}{c}\text { Rs. } 18,000 \text { to } \\
25,000\end{array}$ & 10 & 8 & 18 \\
\hline \multirow[t]{2}{*}{ peryear } & $\begin{array}{c}\text { Rs. } 26,000 \text { to } \\
50,000\end{array}$ & 47 & 30 & 77 \\
\hline & Above Rs. 50,000 & 3 & 2 & 5 \\
\hline
\end{tabular}

administration protocols were provided to the field investigator. The interview was conducted in strict privacy after building rapport with the parents at their residence.

Ethical clearance for the study was obtained from The Leprosy Mission Trust India Ethics Committee, New Delhi. Informed written consent was provided by all participants. The data were entered into a Microsoft Excel database and analysed using SPSS statistics programme. Simple frequencies and distribution measures were calculated for demographic and disease profiles. The differences between groups were analysed with independent ' $\mathrm{t}$ ' test and ANOVA. The threshold for accepting statistical significance was $\mathrm{P}<0.05$.

\section{Results}

Of the one hundred participanting couples, 60 had a male child affected and 40 had a female child affected by leprosy. All the children affected by leprosy were registered at The Leprosy Mission Hospital, Purulia for treatment. The mean age of the female children was 14.4 years (range 8-18 years, with SD 2.713), and for the male children the mean age was 15.1 years (range 10-18 years, with SD 2.220). The mean annual income of the male children's families was 35,267 rupees per year and for female children's families it was 36,475 rupees per year. Seventy $(70 \%)$ fathers had secondary level education, $33 \%$ were farmers, $43 \%$ were working as daily labourers, $16 \%$ were skilled labourers, $5 \%$ were professionals and $5 \%$ were doing business (shown in Table 1).

Of the one hundred children, 67 were diagnosed as multibacillary and 33 were paucibacillary. Forty-six children noticed their skin patch themselves, while in 51 cases the patches were noticed by parents. Forty-nine children had started treatment within six months of noticing the patch;

Ninety children described their first symptoms as a patch; of these, 24 had patches on the face, 36 had patches on the hand, 24 had patches on the leg and 6 had patches on the back. 
Table 2. Disease profile of children affected with leprosy

\begin{tabular}{ccccc}
\hline & Status & Male $(n=60)$ & Female $(n=40)$ & Total $(n=100)$ \\
\hline Disease type & Multibacillary(MB) & 40 & 27 & 67 \\
& Paucibacillary(PB) & 20 & 13 & 33 \\
Treatment status & Released From Treatment (RFT) & 54 & 30 & 84 \\
& Under Treatment(UT) & 6 & 10 & 16 \\
Noticed By & Parents & 31 & 20 & 41 \\
& Self & 26 & 20 & 3 \\
Duration of & Relation & 3 & 0 & 49 \\
symptoms & 1-6 month & 27 & 22 & 40 \\
& 7-12 month & 26 & 14 & 3 \\
First reported at & 13-24 month & 6 & 2 & 78 \\
& 25-36 month & 1 & 2 & 13 \\
& TLM Purulia & 44 & 34 & 9 \\
\hline
\end{tabular}

Weakness of the hand was the first symptom noticed in six children. Two children presented with an ulcer as the first symptom. Seventy-eight children sought treatment at the TLM hospital, 13 reported to the Primary Health Centre (PHC) and 13 children developed grade II deformity at end of their treatment (shown in Table 2).

\section{PARENTS'ATTITUDE TOWARDS THEIR CHILDREN}

The attitude mean item scores are presented in Table 3. Higher scores show greater disagreement with the item as stated, except for items 3 and 7, where a high score shows agreement. Means ranged from 3.83 for "I'm worried that my child will face difficulties in getting a job because of leprosy" (Item 13), to 4.67 for "Children with Leprosy have to be separated from other siblings" (Item 6). Data in the results table indicate that there was an overall positive attitude among parents towards their children affected with leprosy in all the 12 items. Higher positivity showed up in eight of the answered questions, as the mean score was greater than four (Items 1, 2, 3, 4, 5, 6, 9, and 10).

\section{SIGNIFICANT IN ITEMS}

For item number twelve ('I'm worried that my child won't find a good partner to marry because of leprosy"), families with an annual income below 25,000 rupees per year had a significantly higher mean score (4.28), meaning that they were less worried about this issue, than families with an annual income above 50,000 rupees per year $(2.60, p=0.005)$.

For item number nine ("Adults around my child (teachers, neighbours, etc.) treat my child differently than other children"), parents of children aged 8-14 years had a significantly higher mean score (4.58) than for those aged $15-18$ years $(4.27, p=0.05)$. There was no difference between items in relation to disease type, sex and disability grade.

The scores on the single items were summed and divided by the total number of items (12 items). A higher mean score indicates a more positive attitude of parents' towards their child's disease. The summed mean score ranges from 3.1 to 4.8 and the overall mean scores of the study participants were $4.19 \pm 0.34$. The summed mean scores were categorized as; below 3.5 , 3.6-4, 4.1-4.5 and above 4.5. Most parents had a positive attitude towards their child's disease (shown in Table 4). 
Table 3. The mean score of parents attitude towards children illness scale $(n=100)$

\begin{tabular}{|c|c|c|}
\hline S. No & Questionnaires & Mean Score \\
\hline 1 & $\begin{array}{l}\text { Because of Leprosy my child is unable to attend school. } \\
\text { (Strongly Agree, Agree, Neither agree nor disagree, Disagree, Strongly } \\
\text { Disagree) }\end{array}$ & 4.16 \\
\hline 2 & $\begin{array}{l}\text { Because of Leprosy fewer people are coming to our house. } \\
\text { (Strongly Agree, Agree, Neither agree nor disagree, Disagree, Strongly } \\
\text { Disagree) }\end{array}$ & 4.17 \\
\hline 3 & $\begin{array}{l}\text { It is important to administer the medicine on time. }{ }^{*} \\
\text { (Strongly Agree, Agree, Neither agree nor disagree, Disagree, Strongly } \\
\text { Disagree) }\end{array}$ & 4.01 \\
\hline 4 & $\begin{array}{l}\text { Because of Leprosy I try to keep my child away from family gatherings. } \\
\text { (Strongly Agree, Agree, Neither agree nor disagree, Disagree, Strongly } \\
\text { Disagree) }\end{array}$ & 4.50 \\
\hline 5 & $\begin{array}{l}\text { Because of Leprosy my child has no friends. } \\
\text { (Strongly Agree, Agree, Neither agree nor disagree, Disagree, Strongly } \\
\text { Disagree) }\end{array}$ & 4.36 \\
\hline 6 & $\begin{array}{l}\text { Children with Leprosy have to be separated from other siblings. } \\
\text { (Strongly Agree, Agree, Neither agree nor disagree, Disagree, Strongly } \\
\text { Disagree) }\end{array}$ & 4.67 \\
\hline 7 & $\begin{array}{l}\text { I can see success in the treatment of my child. }{ }^{*} \\
\text { (Strongly Agree, Agree, Neither agree nor disagree, Disagree, Strongly } \\
\text { Disagree) }\end{array}$ & 3.91 \\
\hline 8 & $\begin{array}{l}\text { The costs associated with Leprosy treatment is a burden. } \\
\text { (Strongly Agree, Agree, Neither agree nor disagree, Disagree, Strongly } \\
\text { Disagree) }\end{array}$ & 3.92 \\
\hline 9 & $\begin{array}{l}\text { Adults around my child (teachers, neighbours, etc.) treat my child differently } \\
\text { than other children. } \\
\text { (Strongly Agree, Agree, Neither agree nor disagree, Disagree, Strongly } \\
\text { Disagree) }\end{array}$ & 4.41 \\
\hline 10 & $\begin{array}{l}\text { My Child with leprosy is being left out of group activities by other kids. } \\
\text { (Strongly Agree, Agree, Neither agree nor disagree, Disagree, Strongly } \\
\text { Disagree) }\end{array}$ & 4.38 \\
\hline 11 & $\begin{array}{l}\text { I'm worried that my child will face difficulties in getting a job because of } \\
\text { leprosy. } \\
\text { (Strongly Agree, Agree, Neither agree nor disagree, Disagree, Strongly } \\
\text { Disagree) }\end{array}$ & 3.83 \\
\hline 12 & $\begin{array}{l}\text { I'm worried that my child won't find a good partner to marry because of } \\
\text { leprosy. } \\
\text { (Strongly Agree, Agree, Neither agree nor disagree, Disagree, Strongly } \\
\text { Disagree) }\end{array}$ & 3.86 \\
\hline
\end{tabular}

${ }^{*}$ Scoring for the following items is reversed: $3 \& 7$.

Table 4. Distribution of parents' attitude means scores $(n=100)$

\begin{tabular}{lcc}
\hline Mean score & Frequency & Percent \\
\hline Below 3.5 & 4 & $4 \%$ \\
$3.6-4$ & 24 & $24 \%$ \\
$4.1-4.5$ & 60 & $60 \%$ \\
Above 4.5 & 12 & $12 \%$ \\
\hline
\end{tabular}


Table 5. Relationship of parents' attitude scores versus children profiles $(n=100)$

\begin{tabular}{|c|c|c|c|c|c|}
\hline & Status & $N$ & Mean & Std. deviation & $p$ value \\
\hline \multirow[t]{2}{*}{ Gender } & Female & 40 & 4.22 & 0.37 & \multirow[t]{2}{*}{0.55} \\
\hline & Male & 60 & 4.18 & 0.33 & \\
\hline \multirow[t]{2}{*}{ Age } & $8-14$ years & 45 & 4.22 & 0.34 & \multirow[t]{2}{*}{0.54} \\
\hline & $15-18$ years & 55 & 4.17 & 035 & \\
\hline \multirow[t]{2}{*}{ Education } & Continuing & 85 & 4.05 & 0.29 & \multirow[t]{2}{*}{0.08} \\
\hline & Not continuing & 15 & 4.22 & 0.35 & \\
\hline Father & Farmer & 33 & 4.19 & 0.32 & \multirow[t]{4}{*}{0.72} \\
\hline \multirow[t]{3}{*}{ Occupation } & Labourer & 43 & 4.17 & 0.38 & \\
\hline & Skilled & 16 & 4.19 & 0.34 & \\
\hline & Professional \& Business & 8 & 4.33 & 0.26 & \\
\hline \multirow{3}{*}{$\begin{array}{l}\text { Family } \\
\text { income } \\
\text { per year }\end{array}$} & Below Rs. 25,000 & 18 & 4.16 & 0.41 & \multirow[t]{3}{*}{0.89} \\
\hline & Rs. $25,000-50,000$ & 77 & 4.20 & 0.33 & \\
\hline & Above Rs. 50,000 & 5 & 4.16 & 0.38 & \\
\hline \multirow{2}{*}{$\begin{array}{l}\text { Disease } \\
\text { type }\end{array}$} & Paucibacillary (PB) & 33 & 4.20 & 0.40 & \multirow[t]{2}{*}{0.82} \\
\hline & Multibacillary (MB) & 67 & 4.19 & 0.32 & \\
\hline Treatment & Under Treatment (UT) & 16 & 4.36 & 0.26 & \multirow[t]{2}{*}{$0.04 *$} \\
\hline Status & Released From Treatment (RFT) & 84 & 4.16 & 0.35 & \\
\hline Disability & Grade 0 and 1 & 87 & 4.21 & 0.36 & \multirow[t]{2}{*}{0.35} \\
\hline Grade & Grade 2 & 13 & 4.11 & 0.23 & \\
\hline
\end{tabular}

\section{RELATIONSHIP OF PARENTS'ATTITUDE SCORES VERSUS CHILDREN'S PROFILES}

Parents' attitude scores were analyzed in relation to their children's profiles , including gender, age, educational status, father's occupation, family income per year, disease type, treatment status and disability grade (shown in Table 5). The results indicate that there is a significant difference in the parents' attitudes only in relation to treatment status .

\section{Discussion}

This study examined the attitudes of parents towards their children affected by leprosy. For the family, the diagnosis of leprosy in a child can cause mental shock, stress, sentiments of anger, sorrow, and increased intensity in their interpersonal relationships. When parents are more involved in the treatment of leprosy, the chance of impairment and deformity can be minimized or prevented. This study found that the parents of children affected by leprosy had positive attitude towards leprosy.

A skin patch is the first symptom of leprosy in most cases of childhood leprosy. In this study, $90 \%$ had patches as the first symptom and $97 \%$ were noticed either by the children themselves or by the parents. Similar results were found in a previous study in the same area. ${ }^{14}$

Leprosy has a strong association with poverty, ${ }^{15}$ and this is reflected in this study, where $95 \%$ of parents of children affected by leprosy were earning less than fifty thousand rupees yearly. All the children except one had had some education, but fourteen had discontinued their education due to their illness and financial issues. Wealthier parents worried more about a possible inability to find a good partner for their children because of leprosy. Parents of teenagers felt that adults (teachers, neighbours, etc.) around their children treat them differently 
than other children. Parents of treated multibacillary male children with grade 'II' deformity had increased grief towards their child's disease.

Delayed reporting increases the risk of nerve impairment, while early diagnosis and treatment minimizes the impact of disease. In this study, most of the children reported early to the health centres to seek treatment. 50\% reported within six months, and a further $40 \%$ reported between six months and one year after first noticing their symptoms. However, the higher proportion of MB cases (67\%), and disability grade II (13\%) may be due to delay in reporting. Information, education and communication (IEC) activities should be improved in the community, especially in endemic areas, to enhance early voluntary reporting for skin symptoms.

Purulia Hospital has been treating leprosy for more than 125 years, which may explain why a majority of families came there for diagnosis and treatment. Nevertheless, nine families $(9 \%)$ visited private practitioners for their child's treatment, as they easily accessible to the rural people for their illnesses. Disease transmission and complications may be reduced by providing focused orientation and training to private practitioners, especially in high-endemic areas, to help them detect leprosy early and refer for treatment.

In a study in Nepal, Yamaguchi et al. found that parents of adolescents affected by leprosy had higher levels of depression, and lower levels of self-esteem and health related quality of life, compared with parents of adolescents without leprosy. ${ }^{16}$ Jacob et al. assessed attitudes towards leprosy among children with leprosy and their parents, and found that the parents had unchanged or worsened attitude towards leprosy. ${ }^{17}$

This study took place in West Bengal; the findings may not be representative of other areas. Therefore, further comparative work needs to be undertaken on parents' attitude towards their children with leprosy. The PATCIS scale has been tested in the field. Due to resource and time limitations, it has not been retested and validated. Future studies will be needed to investigate its test-retest reliability and to validate the scale. The interviews reported here were conducted with both parernts present; there may be differences in attitude between mothers and fathers, which needs furhter study.

In summary, to the best of our knowledge, this is the first study to investigate parents' attitude towards their children affected by leprosy. The results indicate that they had a positive attitude towards their child's disease. Further research should be multicentre in nature, in order to measure the attitude of parents in different cultures and ethnic groups. Information gained from research may help guide local and national policy on leprosy treatment, such as health education, counselling and awareness programmes. Effective information, education and communication (IEC) may help improve the attitude of parents of children affected with leprosy. This will help in compliance and prevention of impairment and disability. Also, stigma and discrimination can be minimized, starting in the home, with every sibling given equal opportunities in schooling, play, social activities and participation in household work. This will increase the worth and dignity of the affected child and self-stigma will be reduced.

\section{Author contribution}

Dr. Joydeepa Darlong, was involved in study conceptualization and design, preparing the semistructural questionnaires and preparation of the manuscript.

Dr. Pitchaimani Govindharaj, was involved in study design, designing the questionnaires, analysis and interpretation of data and preparation of the manuscript. 


\section{Acknowledgements}

The authors express sincere thanks to Dr. Famkima Darlong, Head - Healthcare, The Leprosy Mission Trust India, New Delhi (Formerly, Superintendent, The Leprosy Mission Hospital, Purulia) for his guidance and encouragement. This study was fully supported by The Leprosy Mission Trust India, Research Domain. We thank Mr. Bhabananda Mahato for his sincere involvement in data collection and management. We also thank Daniel Obergill, volunteer from Germany for his support in initial stages of research.

\section{References}

1 Katoch VM. Recent developments in the diagnosis of leprosy, Expert reviews in molecular medicine. Cambridge: Cambridge University Press; 2002.

2 World Health Organization. Global leprosy update, 2018: moving towards a leprosy-free world. Weekly Epidemiological Record, 2019; 94: 389-412.

3 National Leprosy Eradication Programme (NLEP). Annual Report 2016-17. Central leprosy, Directorate general of health services, Government of India, New Delhi. Available from: http://nlep.nic.in/pdf/ Annual\%20report_\%202016-17_rev.pdf. [Last accessed on 2019 April 24].

4 National Leprosy Eradication Programme (NLEP). District Wise PR \& NCDR as on March 2017. Central leprosy, Directorate general of health services, Government of India, New Delhi. Available from: http://nlep .nic.in/pdf/DisttwiseNCDR-Mar.2017.pdf. [Last aaccessed on 2019 April 24].

5 Darlong J, Govindharaj P, Darlong F, Mahato N. A study of untreated leprosy affected children reporting with Grade 2 disability at a referral centre in West Bengal, India. Lepr Rev, 2017; 88: 298-305.

6 Singal A, Sontalia S, Pandhi D. Childhood leprosy in a tertiary-care hospital in Delhi, India: A reappraisal in the post-elimination era. Lepr Rev, 2011; 82: 259-269.

7 N Govender. Attitudes of parents towards their mentally retarded children: a rural area examination A dissertation for the degree of Master of Arts (Clinical Psychology), Department of Psychology, University of Zululand, 2002.

8 Ahmad M. Comprehensive Dictionary of Education. New Delhi: Atlantic Publishers \& Dist; 2008; p. 41.

9 Nair M, Paul LT, Latha PT, Parukkutty K. Parents' knowledge and attitude regarding their child's cancer and effectiveness of initial disease counseling in pediatric oncology patients. Indian J Palliat Care, 2017; 23(4): 393-398, doi: 10.4103/IJPC.IJPC_83_17. PMID: 29123344; PMCID: PMC5661340.

10 Hazarika M, Das S, Choudhury S. Parents' attitude towards children and adolescents with intellectual developmental disorder. Int J Child Dev Ment Health, 2017; 5(1): 11-21, Epub 2017 Feb 5. PMID: 31131373; PMCID: PMC6530459.

11 Schaffer ES, Bell R. Development of a parental attitude research instrument (PARI). Child Dev, 1958; 29: 339361.

12 Bolarinwa OA. Principles and methods of validity and reliability testing of questionnaires used in social and health science researches. Niger Postgrad Med J, 2015; 22: 195-201.

13 Terwee CB, Bot SDM, de Boer MR et al. Quality criteria were proposed for measurement properties of health status questionnaires. J Clin Epidemiol, 2007; 60: 34-42.

14 Govindharaj P, Darlong J, John AS, Mani S. Children and adolescents' attitude towards having leprosy in a high endemic district of India. Lepr Rev, 2016; 87: 42-52.

15 Kerr-Pontes LRS, Montenegro ACD, Barreto ML, Werneck GL, Feldmeier H. Inequality and leprosy in Northeast Brazil: an ecological study. Int J Epidemiology, 2004; 33: 262-269.

16 Yamaguchi N, Poudel KC, Jimba M. Health-related quality of life, depression, and self-esteem in adolescents with leprosy-affected parents: results of a cross-sectional study in Nepal. BMC Public Health, 2013; $13(1): 1$.

17 Jacob MS, Amar D, Christopher A, Keystone JS. Transmission of health information on leprosy from children to their families in an urban centre. Lepr Rev, 1994; 65: 272-278. 